\title{
MODELING SINGLE ESTABLISHMENT FIRM RETURNS TO THE 2007 ECONOMIC CENSUS
}

\author{
by \\ Emin M. Dinlersoz * \\ U.S. Bureau of the Census \\ and \\ Shawn D. Klimek * \\ U.S. Bureau of the Census
}

CES 11-28

September, 2011

The research program of the Center for Economic Studies (CES) produces a wide range of economic analyses to improve the statistical programs of the U.S. Census Bureau. Many of these analyses take the form of CES research papers. The papers have not undergone the review accorded Census Bureau publications and no endorsement should be inferred. Any opinions and conclusions expressed herein are those of the author(s) and do not necessarily represent the views of the U.S. Census Bureau. All results have been reviewed to ensure that no confidential information is disclosed. Republication in whole or part must be cleared with the authors.

To obtain information about the series, see www.census.gov/ces or contact Cheryl Grim, Editor, Discussion Papers, U.S. Census Bureau, Center for Economic Studies 2K130B, 4600 Silver Hill Road, Washington, DC 20233, CES.Papers.List@census.gov. 


\begin{abstract}
The Economic Census is one of the most important activities that the U.S. Census Bureau performs. It is critical for updating firm ownership/structure and industry information for a large number of businesses in the Census Bureau's Business Register, impacting most other economic programs. Also, it feeds into Bureau of Economic Analysis products, such as benchmark input output accounts and Gross Domestic Product. The overall check-in rate for the 2007 Economic Census was just over 86\%. Establishments owned by multi-location companies returned over $90 \%$ of their forms, as compared to the roughly two million single-establishment firms sampled in the Census that returned just over $80 \%$. We model the check-in rate for single-establishment firms by using a large number of variables that might be correlated with whether or not a firm returns a form in the Economic Census. These variables are broadly categorized as the characteristics of firms, measures of external factors, and features of the survey design. We use the model for two purposes. First, by including many of the factors that may be correlated with returns we aim to focus limited advertising and outreach resources to low-return segments of the population. Second, we use the model to investigate the efficacy of an unplanned intervention expected to increase return rates: using certified mailing for one of the form follow-ups.
\end{abstract}

Keywords: Economic Census, multivariate analysis, paradata, responsive design

JEL Codes: C81

* Any opinions and conclusions expressed herein are those of the authors and do not necessarily represent the views of the U.S. Census Bureau. All results have been reviewed to ensure that no confidential information is disclosed. The authors thank Mike Kornbau, Fane Lineback and seminar participants at the Census Bureau for many helpful comments. The authors also acknowledge Shelley Karlsson for providing metadata/paradata and answering many detailed questions about mail-out/mail-back of the 2007 Economic Census. 


\section{Introduction}

The Economic Census is the second largest data collection project at the U.S. Census Bureau after the Decennial Census. It provides a detailed picture of the U.S. economy every five years in terms of industry, geography, and over 20,000 data items collected on more than 500 forms. The Economic Census is also critical for updating the Business Register (BR), the sampling frame for nearly every business survey conducted by the Census Bureau. In particular, it collects firm ownership and structure and detailed industry information at the establishment level.

In this paper, we investigate factors that are correlated with the likelihood of form return by establishments in response to 2007 Economic Census mail-out. We use the terms check-in and return interchangeably. We define check-in to be equal to 1 if an establishment returned a form to the Census Bureau and equal to 0 otherwise. It is not meant to be confused with a response. ${ }^{1}$ In the 2007 Economic Census, the check-in rate of single-establishment firms (81\%) was significantly lower than the rate for establishments owned by multi-establishment firms (91\%). This is probably due in part to a long standing interest in easing respondent burden and facilitating returns for large companies, which represent a disproportional amount of the activity in the U.S. economy (Willimack (2002)). Single-establishment firms represent a large share $(43 \%)$ of the total number of establishments sent a form in the Economic Census, roughly 2 million out of the 4.6 million total forms mailed. ${ }^{2}$ We also only analyze the short and long census forms that collect detailed data for each establishment, dropping "classification" forms that only

\footnotetext{
${ }^{1}$ A response also takes into account the quality of the reported data for a pre-defined set of data items.

${ }^{2}$ The total universe of establishments is roughly 7 million. All establishments owned by multi-establishment firms are certainty cases, but the economic "census" samples single-establishment firms in most sectors.
} 
collect detailed NAICS industry information. ${ }^{3}$ Since we focus only on single-establishment firms, we use the terms establishment and firm interchangeably.

In 2008 , substantial changes were made to the mail-out plan aimed at increasing returns for this large group of firms since they were critical for reaching the overall check-in rate goal for the 2007 Economic Census. ${ }^{4}$ These interventions demonstrate the flexibility of the program managers to be able to adapt to unexpected declines in check-in rates. In many instances, testing the efficacy of these interventions for the Economic Census occurs in other programs, such as the Annual Survey of Manufactures (ASM) or sometimes current surveys in non-manufacturing sectors. Neither of these is exactly comparable to the Economic Census due to differences in scope and the definition of the reporting units, so using model based propensity score matching is a way to test the benefits of these interventions in the Economic Census ex post.

The primary purpose of this paper is to develop a new multivariate analysis of small firms returning the short or long forms to the Census Bureau in the 2007 Economic Census. The model is being used as an additional source of information to better focus limited publicity, outreach, and fiscal resources to maintain or raise return rates in the 2012 Economic Census. We also use the model to better evaluate the efficacy of one treatment during the Census - sending the third form follow-up via certified mail. The model we construct will also be used to predict returns for 2012 Economic Census and to track and analyze differences between the predicted and actual check-ins in "real-time" during data collection.

\footnotetext{
${ }^{3}$ Roughly one million classification forms were mailed in 2007 , with a final check-in rate of $88 \%$.

${ }^{4}$ The Program Assessment Rating Tool (PART) is an assessment rating system developed by the Office of Management of Management and Budget to grade the effectiveness of federal agencies and federally funded programs. The PART score for the 2007 Economic Census check-in rate was 86\%.
} 


\section{The Literature}

Our approach is similar to that used by the Center for Economic Studies to analyze the 2010 Decennial Census tract level return rates for the mail-out/mail-back operation and model enumerator level productivity during non-response follow-up operation. We model the likelihood that a firm mails their form back as a function of the characteristics of the firm, the local economic conditions, the characteristics of the survey design, and additional controls (industry and geography).

The survey methodology literature on modeling business survey response seems much less common than the literature for demographic surveys. One exception is Biffignandi and Pratesi (2002) who model the response rates to a web-survey in Italy. They model non-response using a logistic regression model with crude measures of size and industry and legal form of organization. They also model the time to respond. We are unable to exactly measure the time to respond in the 2007 Economic Census. We know when forms are returned (i.e., checked-in), but we only have a range of dates for mail-out. In 2012, additional paradata is being captured on the exact times when forms enter the postal stream that will allow us to exactly measure the time to respond and extend our analysis.

The check-in rate measures the share of establishments that returned a form, and should not be confused with the response rate or a participation rate. Petroni et. al. (2004) describes the response rate measures used by both the Bureau of Labor Statistics (BLS) and the Census Bureau. Current efforts within the Census Bureau's Economic Directorate aimed at defining the response rate for the Economic Census and developing a cooperation rate (as a real-time proxy 
for the response rate) are ongoing, and upon completion could easily be incorporated into our analysis.

In 2002, changes to the design of the Economic Census forms resulted in substantial differences in the number of pages compared to 1992 and 1997 forms. Willimack (2006) provides a useful background section describing the change to the forms and the Economic Census program overall. In 2007, the forms were designed by the same system using the same basic guidelines and are comparable to $2002^{5}$. Willimack (2006) looks at the relationship between form-level return rates and questionnaire length, controlling for within sector economic factors (specifically changes in GDP and changes in employment). She finds that form length has a negative relationship with early return rates. However, the changes to the forms did not have a substantial impact in 2002 , as the effect of page length was smaller than in the previous two censuses.

\section{The Economic Census}

The Economic Census is a program that combines collected data with administrative records to measure economic activity of U.S. business establishments. It is conducted every five years, with reference years ending in " 2 " and "7". The actual data collection occurs primarily in the year after the reference year.

In 2007 , there were roughly 7 million establishments and roughly 4.6 million $(\sim 66 \%)$ of them were sampled in the census. The establishments owned by multi-establishment firms are sampled with certainty (i.e., with a sampling weight of 1), which number roughly 1.6 million and

\footnotetext{
${ }^{5}$ The overall "look and feel" and content of the forms was very similar in 2002 and 2007, while some of the wording and order of items may have changed.
} 
account for the majority of business activity. Another 3 million single establishment firms are also mailed Economic Census forms - roughly 1 million are mailed industry classification forms that only collect industry and 2 million are mailed short or long forms that collect detailed data. In this paper, we study only single-establishment firms that are mailed a short or long form.

The Economic Census is carried out using two modes of data collection. The first is a standard mail-out/mail-back paper instrument and the second is an electronic reporting tool called "Surveyor" which is designed to facilitate reporting by multi-establishment firms, but is available to all respondents. ${ }^{6}$ The two million single-establishment firms reported electronically roughly $2 \%$ of the time, so we ignore mode and focus only on whether or not a (paper or electronic) form was returned. The initial mailing occurred at the end of December 2007, with up to four follow-up mailings in 2008. Table 1 shows the follow-up mailings were in midMarch, late April, June, and early August. In general, firms are mailed a form at each mailing, except for the final follow-up which is a letter. Figure 1 shows the cumulative return rate during the mail-out/mail-back phase of the Economic Census. The shaded bars are the initial and follow-up mailings and the red line indicates the February 15, 2008 deadline for responding.

${ }^{6}$ For electronic reporting in 2012, single-establishment firms will only be offered a web-based direct internet reporting (DIR) instrument whereas multi-establishment firms will only be offered the option to report using Surveyor. 
Figure 1: Cumulative check-in rate over time

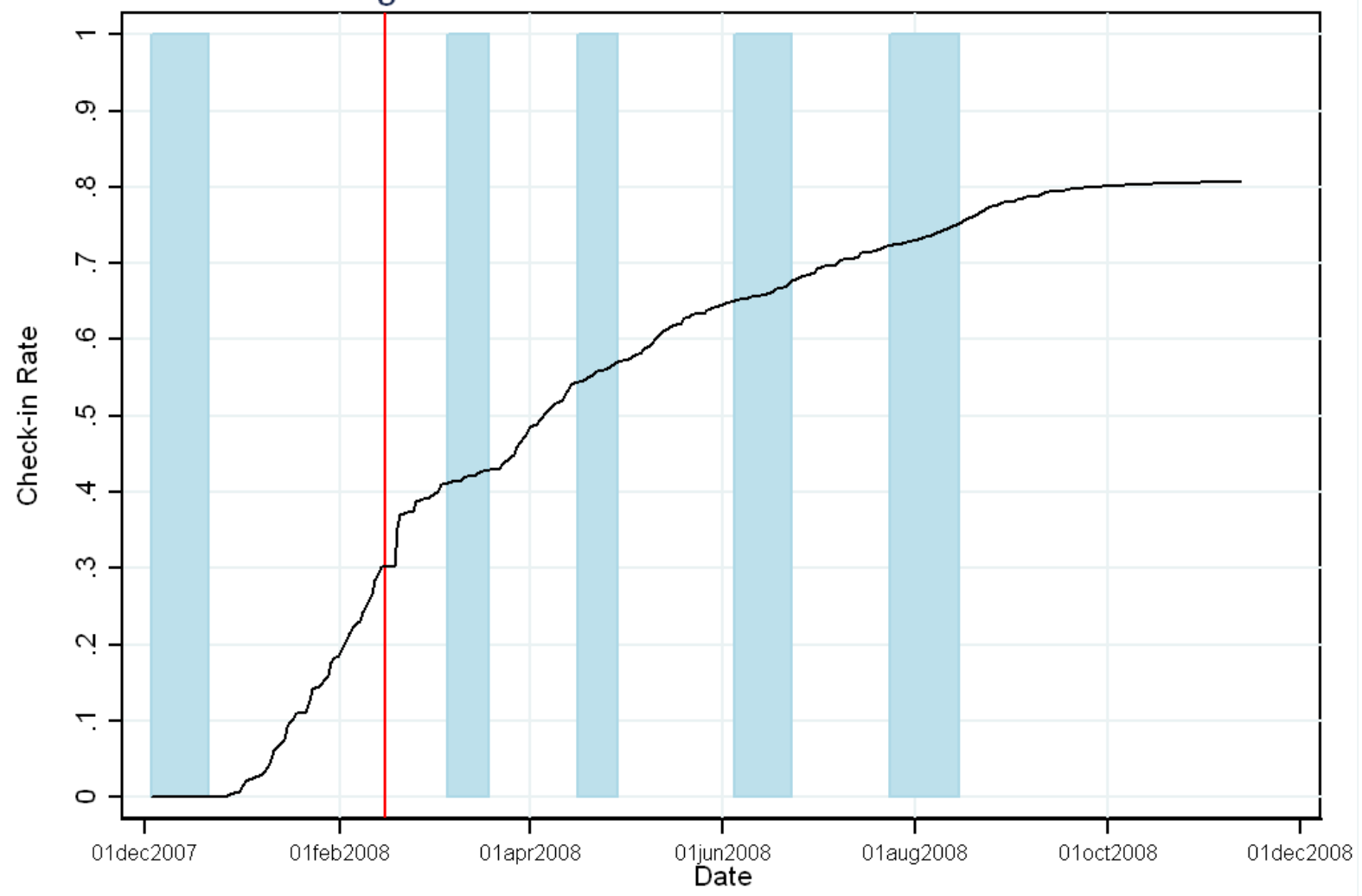

For 2007, two mail interventions were conducted to encourage late returns to achieve Economic Census program goals. The first was during the third follow-up where 34 form types were mailed using certified mail instead of first class postage, in an effort to distinguish the census mailing. The second was sending a letter during the fourth follow-up, instead of a form. This letter reminded respondents about their legal obligation to report in the mandatory Economic Census and the possible penalties for failing to do so. This letter was not from a Census Bureau official, but from the Department of Commerce's Office of the Inspector General (OIG). Unlike the certified mailing, the OIG letter was sent to virtually every delinquent firm and therefore we can't test how effective the strategy was. 


\section{Methodology and Data}

We incorporate characteristics of the business, measures of the external environment, and survey design that their work describes as the important factors affecting large company returns. We do not provide a formal model of small firm behavior to describe who does or does not return their Economic Census form. We loosely follow the framework set out in Willimack et. al. (2002), where large firms compare the costs and benefits of completing and returning their form. We consider this analysis of single-establishment firms as a complement to their work.

Analyses of check-in rates for Economic Census planning purposes generally uses tabulations at the industry or geographic level - a univariate approach. These aggregates may be broken out by multi-establishment versus single establishment firms. "Third-quarter births" are another distinction made in weekly progress reports. ${ }^{7}$ Using a model-based approach, we are able to simultaneously control for a large range of factors that could potentially influence whether or not an establishment returns a form. Our hypothesis is that characteristics of the establishment, factors external to the firm and characteristics of the survey design may influence whether or not the business returns a form. For example, one hypothesis is that larger firms are more likely to return a form than smaller firms.

The data used in this analysis comes primarily from Economic Census microdata and paradata. Paradata is information collected about the conduct of the Economic Census and examples in this study are the dates forms were checked in at the Census Bureau's processing facility and the content of the instruments. We also match additional information, generally by

\footnotetext{
${ }^{7}$ Administrative data from the IRS is used to determine which businesses are active during the reference year. At the time of the initial mailing in December 2007, only first and second-quarter administrative data are available. Third-quarter births are those firms that first report during the third quarter and these firms differ in terms of when they are mailed and how many times they can be followed up.
} 
geography, to investigate hypotheses such as whether or not the local economic conditions, such as the unemployment rate, are important factors for check-ins. Working with program area staff, we identified eleven groups of variables to describe the characteristics of the business, external factors, and survey design. Recall that one part of this exercise is to inform management where to devote limited resources to maintain or improve return rates in 2012.

Table 2 describes the variables in our model. We measure the characteristics of the business: prior reporting status in 2002, age, size, industry, geography, and owner characteristics. These are factors we control for since they may be correlated with whether or not a firm returns a form. We describe some of the more interesting patterns of firm returns for a subset of these variables.

Figure 2: Cumulative check-in rate over time

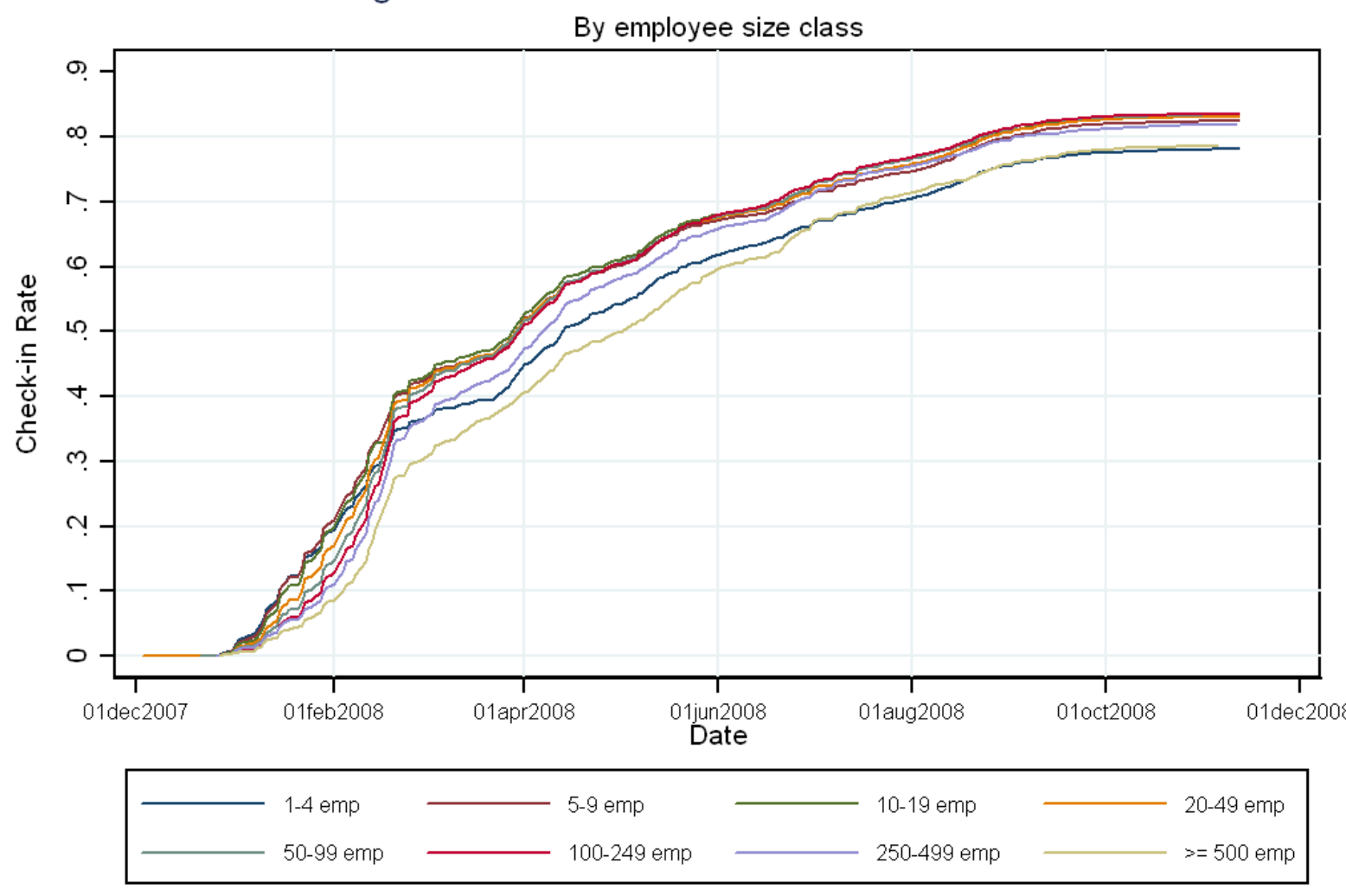


We use employment as a measure of firm size and create size categories. Figure 2 shows the cumulative returns over time for each size class. Our hypothesis is that the smaller the firm, the less likely they are to complete their Economic Census form. As firm size increases, we expect them to be more likely to respond. As expected, the group that responds the worst at closeout is the smallest size group, 1-4 employees. The surprising result is the largest single-establishment firms with over 500 employees perform similarly to the smallest size class; they even lag behind initially but eventually bridge the gap by close-out. The other size categories between 5-499 employees are for the most part grouped together and perform better than these two groups by late February. The group with 250-499 employees lags behind initially, but catches up to the other groups between 5-249 employees by late June.

In addition to size, we also want to account for the age of the firm. We match firms to the Longitudinal Business Database (LBD) in order to identify firm age and then break the age distribution into six categories. Our hypothesis is that the older a firm, the more likely it is to respond in the Economic Census. This is partly because size and age are positively correlated, but also because older firms would be more likely to have knowledge of the Economic Census and/or to have responded to an earlier census. In the model, we control for size and age, as well as prior experience with the Economic Census in 2002. Figure 3 clearly shows a strong relationship between age and return rates, with younger firms the least likely to respond and older age classes more likely to respond in a monotonic fashion. This relationship begins to hold shortly after the February 15, 2008 reporting deadline and continues until closeout. 
Figure 3: Cumulative check-in rate over time

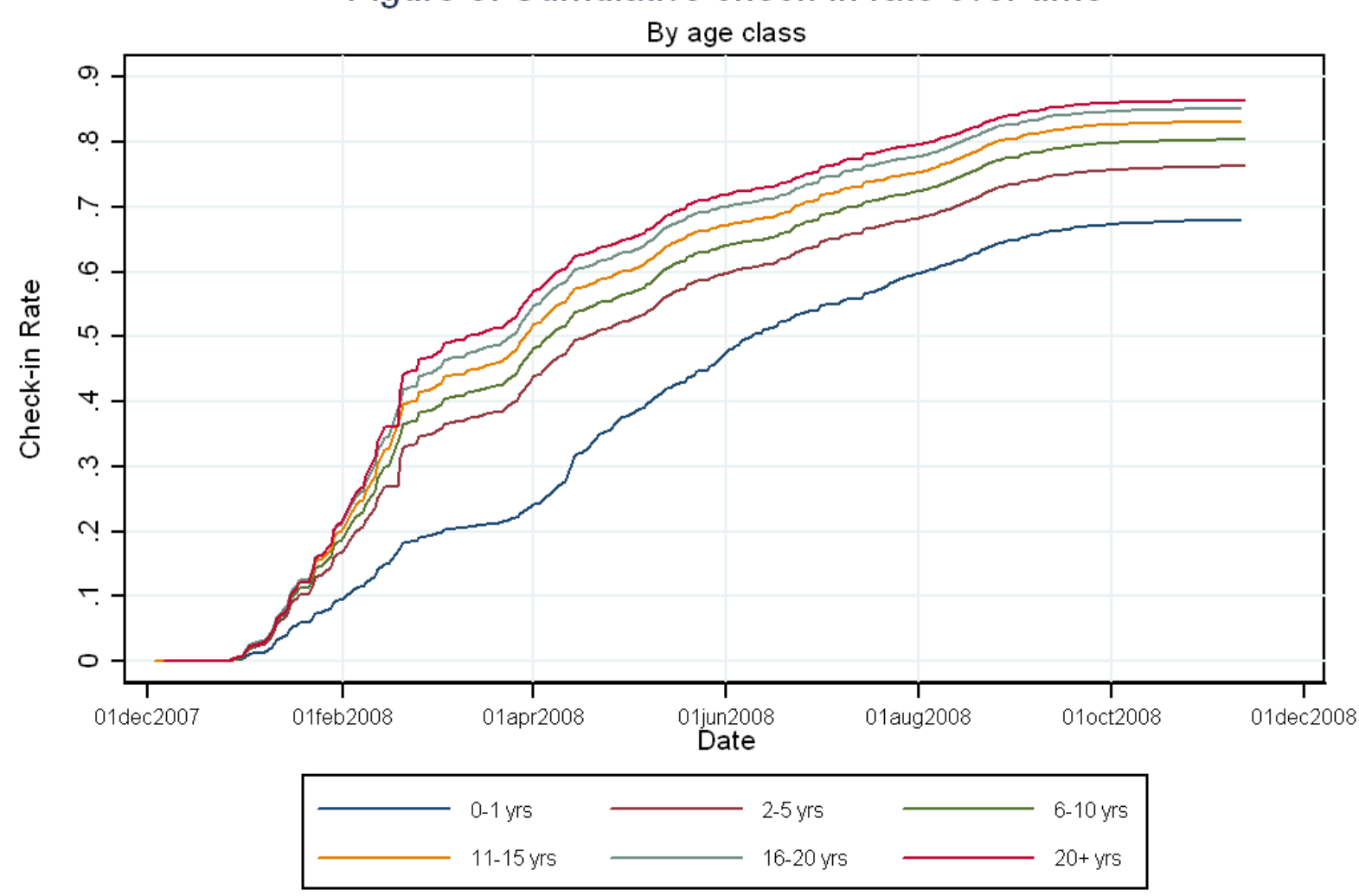

Another characteristic we control for is the race or gender of the owner. We know that the return rate for the 2007 Survey of Business Owners (SBO) was significantly lower than that of the Economic Census. Using indicators of race/ethnicity/gender from the $2007 \mathrm{SBO}$ frame, we track the returns of likely Asian, Hispanic, Black and female owned businesses. ${ }^{8}$ As figure 4 shows, women-owned businesses perform better than any other group. The other three groups all perform worse, with Hispanics responding at the lowest rates.

\footnotetext{
${ }^{8}$ The SBO assigns each business owner to a single race, ethnicity, or gender frame depending on the highest likelihood among all the frames the business owner can be classified into, based on collected and administrative data. For example, a Black female business owner would most likely be in the Black frame or the female frame, but not both. To account for multiple classifications such as a "Black female" business owner, in section 5, we include the likelihood of a business owner being classified into a race or ethnicity category, and also separately include the likelihood of being classified as female or Hispanic, since these characteristics are not mutually exclusive.
} 
Figure 4: Cumulative check-in rate over time

By SBO frame type

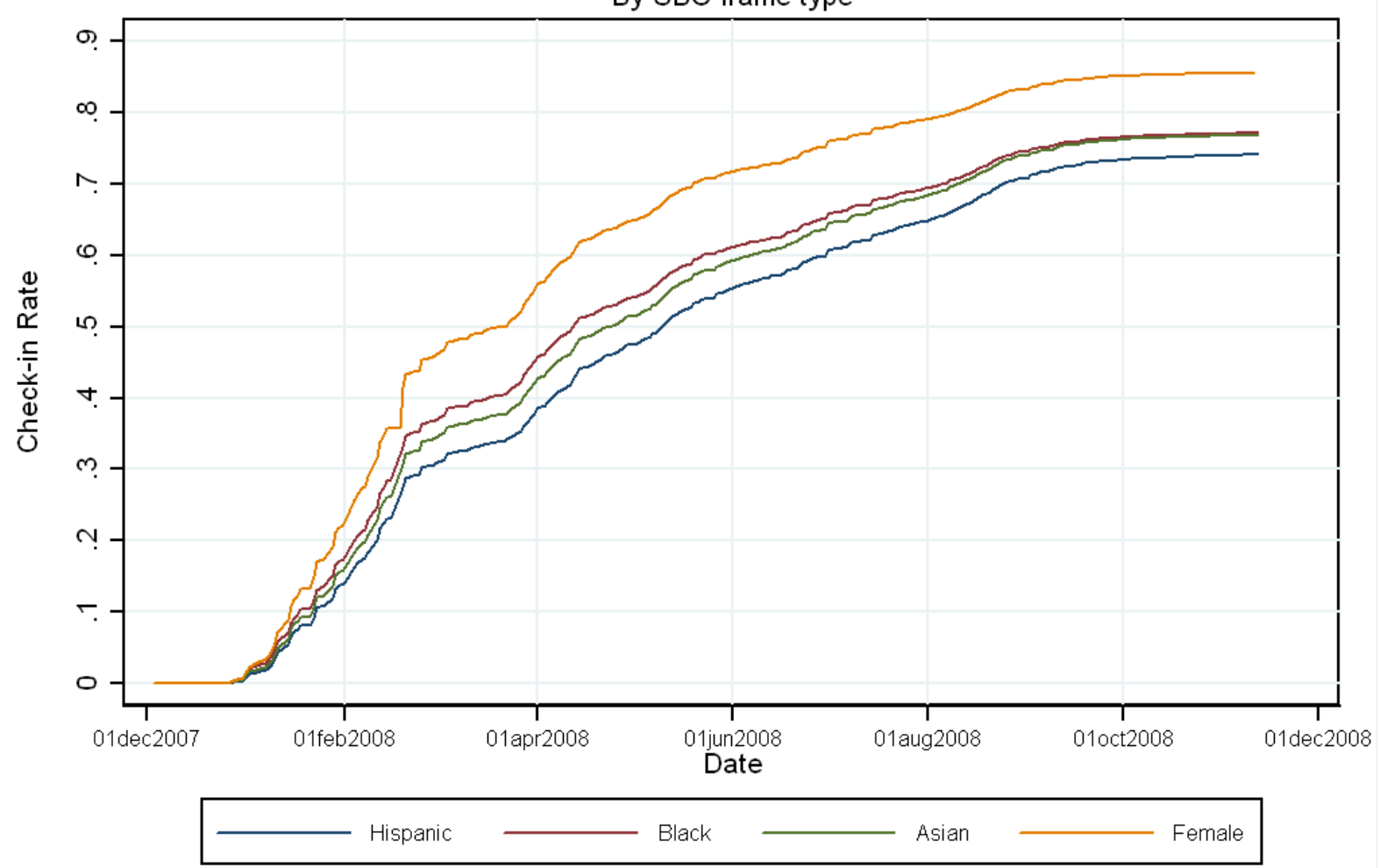

We also measure the external conditions using aggregate data matched using geographic identifiers. We use the county unemployment rate level and change from 2002 to 2007, as well as the size of the labor force in each county. We also proxy "attitudes towards the Census Bureau" by adding 2010 Decennial Census return rates at the census tract level. Additional tract level variables include median income, share of population Asian, share of population Black, share of population Hispanic, and finally percent of the population that is linguistically isolated ${ }^{9}$.

\footnotetext{
${ }^{9}$ The Census Bureau defines a linguistically isolated household as on in which no one 14 years old and over speaks only English or speaks a non-English language and speaks English "very well."
} 
Imperfect coding of addresses to the tract level means that using these variables results in dropping a significant number of observations, so we ran specifications with and without them.

Finally, we calculate measures of survey methods using the available paradata and metadata. We measure the quality of the Business Register in two ways: the source of the industry code and the quality of the mailing address. We also measure the characteristics of the Economic Census instruments. The previous variables describe firm characteristics that the Census Bureau must take as given, whereas the latter variables are for the most part determined by Census and are possibly affected by changes to the program (e.g., changing the content of the forms).

We describe in detail one indicator of Business Register quality: the source of the NAICS industry code. We create four variables to describe the source: a Census-based code, a Bureau of Labor Statistics (BLS)-based code, a Standard Statistical Establishment List-based code, and an industry code from another non-BLS administrative code. ${ }^{10}$ Current BR processing rules rank Census-based codes as the best source followed by codes from the BLS. Our hypothesis is that establishments with industry codes from these sources should perform similarly, with the Census-based codes perhaps being slightly better.

The return rate for establishments with Census-based codes was over 13\% higher than for establishments with BLS-based codes. BLS industry codes come from state-based ES-202 Unemployment Insurance programs, and the industry is in part used to determine the premiums. We therefore delve a little deeper and explore variation across states/industries between BLS and Census industry codes. Interestingly, we find that Census-based industry codes perform better in

\footnotetext{
${ }^{10}$ The Standard Statistical Establishment List (SSEL) is the previous name for the BR, which was migrated to a new system in late 2001. The SSEL-based codes are those assigned prior to this migration, with the vast majority of them being Census-based codes assigned in the 1997 Economic Census which was also the first collected on a NAICS basis.
} 
all 50 states and the District of Columbia, ranging from $8 \%$ (DC) to $18 \%$ (WY). Figure 5 shows the distribution of return rates by industry. We find that Census Bureau industry codes average $86 \%$ return rate. The average industry return rates, if the codes are from the BLS, is $72 \%$ and exhibits more variation. While a few industries have higher return rates if the codes are sourced from the BLS, the industry rates of return are on average about $14 \%$ higher if the code is sourced from the Census Bureau.

Figure 5: Check-in rates by 6-digit NAICS industry Census industry codes vs. BLS administrative source industry codes

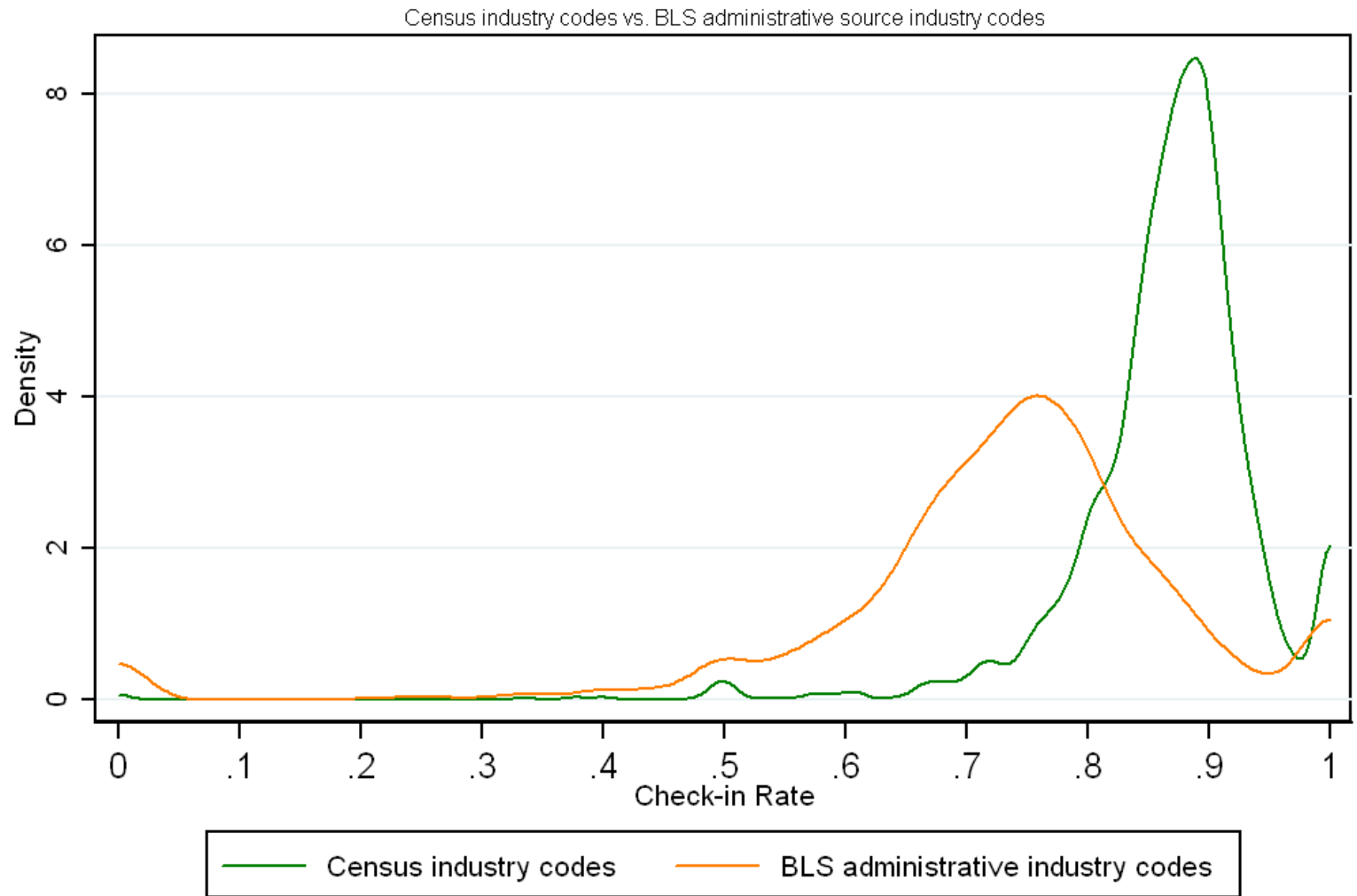

Indicators of the quality of the BR address are the incidence of "Undeliverable-AsAddressed" (UAA) and the ability of the Census Bureau's Geography Division to successfully code the address to the Census tract level. We also try to control for differences in mailing packages, since there are over 500 different form types. We summarize this variation using the 
number of pages, the total number of items, the number of "industries" covered by each form, and the share of items that fall into different categories: write-ins, check-boxes, or dollar values. For the most part, single-establishment firms are mailed according to the same schedule in the Economic Census. We can measure some differences such as certified mailings for some form types, third-quarter births, and whether or not the firm was granted an extension on the deadline to report.

\section{Model Results}

In many respects, the Economic Census is distinct from other economic programs in that reporting units are establishments. Annual, quarterly, and monthly (current) surveys for retail, wholesale, and/or services are based on firms and EINs in combination with industry. Like the Economic Census, the Annual Survey of Manufactures (ASM) reporting units are establishments, and for that reason it is often used to test changes to the Economic Census. However, the single-establishment firms in the Economic Census are dominated by nonmanufacturing industries so the ASM seems inappropriate for testing strategies to improve returns, as do the current surveys outside of manufacturing since they are not based on the establishment. There is also tremendous heterogeneity in the forms that are distinct to the Economic Census, which is another reason why it is difficult to compare with other programs. We want to take characteristics of the survey design into account and it is unclear that we'd be able to control for the variation in Census forms using information from other programs. The ASM, for example, only mails one type of form as compared to the Census of Manufactures which mails hundreds of different forms with many detailed inquiries about material inputs and product outputs. 
Since other surveys may be inappropriate for testing survey design changes to the Economic Census, it is even more important to use as much information as possible from the Economic Census itself. Developing a model of the check-in status will provide the foundation for evaluation, which we describe in section 5.1. In section 5.2, we use the model to evaluate one of the strategies expected to raise return rates in 2007: a certified mailing form follow-up.

\subsection{Analysis of Return Rates}

Following Greene (2008), we estimate the check-in status using a logit model with the independent variables described in the data section and listed in table 2. The basic variable of interest, check-in status, is whether or not a firm mailed back their form. The indicator variable, $C I_{j}$, takes on a value of 1 if firm $j$ returned their form and 0 otherwise. We model this variable as a function of the characteristics of the business, the external environment, and the survey design, represented by $x_{j}$.

$$
\operatorname{Pr}\left(C I_{j}=1 \mid x_{j}\right)=\frac{\exp \left(x_{j} \beta\right)}{1+\exp \left(x_{j} \beta\right)}
$$

The full results are presented in table 3 , where we report the odds ratio and standard errors for all of our independent variables for several specifications. An odds ratio of 1 implies that the event is equally likely as it is for the omitted group. An odds ratio greater than one implies that the event is more likely and an odds ratio less than one implies that the event is less likely. In this section we describe some of the highlights. These results include controls for both industry and geography, as well as taking into account both the sampling weights and strata. The statements below are not causal, but can be interpreted as correlations with a rich set of controls. The statements are made holding everything else in the model fixed. 
First, we look at the relationship between the characteristics of the business and whether or not they return a form. Calculating the check-in rates by size category shows an inverted Ushaped distribution, where form returns are low for the smallest size group then rise as size increases, but decline for the largest categories of firms which actually do worse than smallest category. Figure 2 clearly showed this pattern in the raw data for the largest group. The model corroborates the pattern for the largest group and also indicates that, controlling for other factors, firms with more than 250 employees perform significantly worse than the smallest size category of 1-4 employees. This inverted U-shaped pattern seems puzzling, but could be explained if larger firms are both resource constrained and sufficiently complex that reporting is quite burdensome. In 2007, multi-unit return rates were highest for the largest companies and lowest for the smallest, so this result could also be seen as a continuation of the pattern for the overall size distribution of firms.

The odds ratios for the age categories indicate that all age groups perform better than the youngest group ( $0-1$ years, the omitted group), and the check-in rates are increasing with age. We include not just gender/ethnicity/race indicator variables, but also the likelihoods of being in each category from the frame as well. Specifically, we include the probabilities of being classified as Hispanic or Female. We also include two race indicators, Asian and Black, as well as interaction of these indicators with the probabilities of being classified in these races. The omitted category is all other SBO frame groups including Female, Hispanic, American Indian, Hawaiian, national (e.g., white males), and other. The results are consistent with women owners being more likely to return their form and Hispanic owners less likely. Blacks and Asians have lower likelihoods relative to all other firms not in these groups. 
We also include a range of variables that fall into the external factors group. We find a number of robust results. The higher the unemployment rate in the county, the less likely the firm is to respond. When we include tract-level characteristics, we also find that they are important. The 2010 Decennial Census mail-back return rates, meant as a proxy for "local attitudes towards the Census Bureau", are an important factor. The 2007 returns are positively associated with 2010 returns. Variables for the shares of minority population and linguistically isolated are all negatively correlated with firm returns in the Economic Census.

The final group of factors is what we call "survey methodology" variables, and they describe variation across firms in how the census was conducted. Earlier in the paper we discussed the observed difference in return rates from different administrative sources in the BR by industry and geography. The check-in rates were consistently lower for establishments with BLS codes as compared to those with Census codes. In the model, we include both the check-in status of the firm in the 2002 Economic Census and the source of the industry code. Returning a form in 2002 is highly correlated with returning a form in 2007, relative to the non-mail cases in 2002. We also find that establishments with BLS codes are significantly less likely to return a form.

Since firms that didn't return a form in 2002 must almost certainly have a BLS code prior to the 2007 Economic Census, we fully interact the firm's status in 2002 \{nonmail, mailednonresponse, mailed-returned form $\}$ with the source of the industry code \{Census, administrative data - BLS, administrative data - non-BLS\}. When interacted with the "2002 non-mail" indicator, we find that establishments with BLS sourced industry codes perform worse relative to Census derived industry codes. 
We also look at the effect of the establishment missing a tract code and the establishment being assigned as Undeliverable-As-Addressed (UAA). The variables "no tract x UAA", "tract $\mathrm{x}$ no UAA", and "tract x UAA" are the interaction of the establishment missing a tract code and UAA, with the omitted group of the firm being assigned a Census tract and not having a UAA status. All three groups are less likely to respond, but UAA status matters the most, as one would expect. ${ }^{11}$

The set of variables that describe the survey instrument are in general not significant, with the exception of number of pages, but not a very large effect, with an odds ratio of $\sim .94$. This finding is consistent with Willimack (2002).

\subsection{Analysis of Certified Mailing Treatment}

In 2007, approximately 130,000 single-establishment firms were mailed a third follow-up using U.S. Postal Service certified mailing, at a cost of $\$ 4 /$ package versus $\$ .50 /$ package using standard mail. ${ }^{12}$ Appendix A provides a list of form types and counts subject to this treatment. ${ }^{13}$ Since this was not a planned randomized experiment, we will use our model results from section 5.1 to evaluate the cost effectiveness of the certified mailing. We use nearest neighbor matching as described by Smith and Todd (2005) in identifying a group of controls to be compared with the firms which were included in the certified mailing (the treatment group). In their review of the propensity score matching literature in labor economics, they summarize three criteria from Heckman, Ichimura and Todd (1997) and Heckman, Ichimura, Smith, and Todd (1998) that limit

\footnotetext{
${ }^{11}$ In the paradata, we observe cases where UAAs are mailed multiple times, but they are not always returned by the U.S. Postal Service as UAA. This is why UAA status=yes doesn't perfectly predict nonresponse.

${ }^{12}$ We exclude Island Areas. The cost difference times the form counts in Appendix A imply that this treatment cost over $\$ 450,000$. Current plans for 2012 economic census call for sending 160,000 forms via certified mail.

${ }^{13}$ The EC has over 500 form types and mails millions of forms during mailout/mailback operation. Mailout has to be "batched" by form type, so the more form types mailed via certified mailing, the higher the overall cost.
} 
the bias when using these methods: (i) the same data sources (i.e., the same surveys or the same type of administrative data or both) are used for participants and nonparticipants, so that earnings and other characteristics are measured in an analogous way, (ii) participants and nonparticipants reside in the same local labor markets, and (iii) the data contain a rich set of variables that affect both program participation and labor market outcomes.

As these studies apply to demographic data on workers, we will translate them to our business data. First, our data comes from the same source(s) - both treatment and control propensities are derived using administrative data to construct characteristics of the businesses, external factors are linked using geographic identifiers, and metadata and paradata sources describe differences in survey methods for all businesses in the Economic Census. Second, while we do not have "local labor markets," we do classify firms into industries. We are unable to restrict the matches to be within the same NAICS industry, since form types match closely to detailed industry. We explored the idea of matching at the two-digit or four-digit level, but at the time of the third mailout, there were simply too few potential donors for each treatment. Table 1 shows the number of total mail cases and the number of certified mail cases in the third followup. Finally, the certified mail cases were selected by form type so we know exactly how firms were selected for participation, and we have a rich set of variables that describe whether or not a firm responds in the Economic Census. Given all of these factors, we feel that using propensity score matching to evaluate this treatment in the Economic Census is feasible, although inferior to the first best method of using an experimental design to randomly select firms from each form type. 
We use nearest neighbor matching with replacement. For each treated firm $i$, we select a control firm $j$ from the set of potential controls, $I_{0}$, so that the control firm is closest to the treated firm in terms of the predicted probability of return calculated from the logit model

$$
C\left(P_{i}\right)=\min _{j}\left\|P_{i}-P_{j}\right\|, j \in I_{0} .
$$

$P_{i}$ and $P_{j}$ are predicted probabilities using the model from table 3 , but run only for the firms that still hadn't returned a form at the time of the third follow-up. $I_{0}$ is defined as all singleestablishment firms which were not included in the certified mailing and had not mailed back a form by June 4, 2008, the first date that certified mail cases were selected as shown in Appendix A. In addition, they can't be classified as third quarter births or have an unexpired extension on June 4. 
Figure 6: Predicted check-in rates for treatment group and potential controls

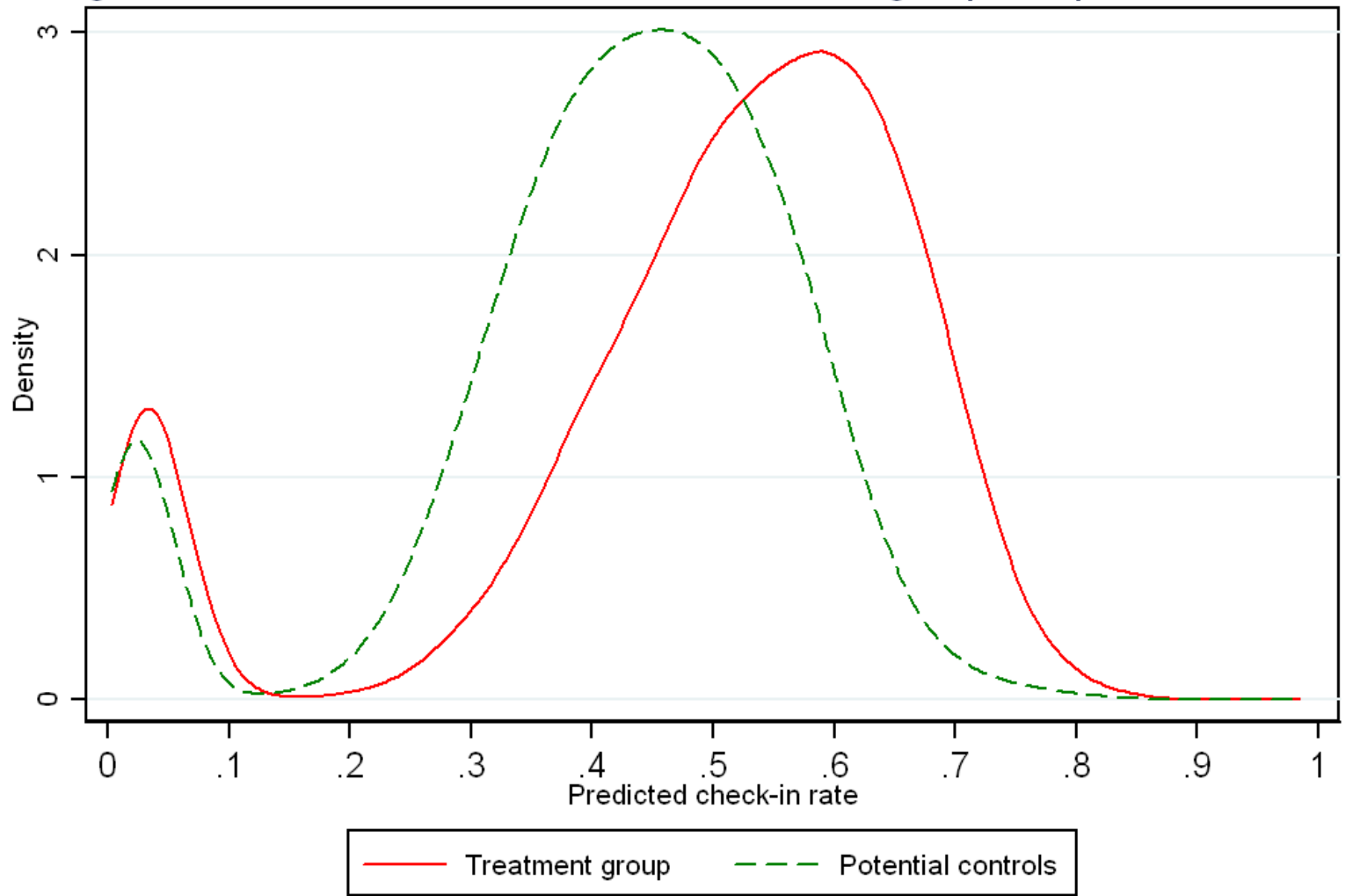

Figure 6 shows the nonparametric kernel density estimates of predicted probabilities for the treated firms and the set of potential control firms. 
Figure 7: Predicted check-in rates for treatment and control groups

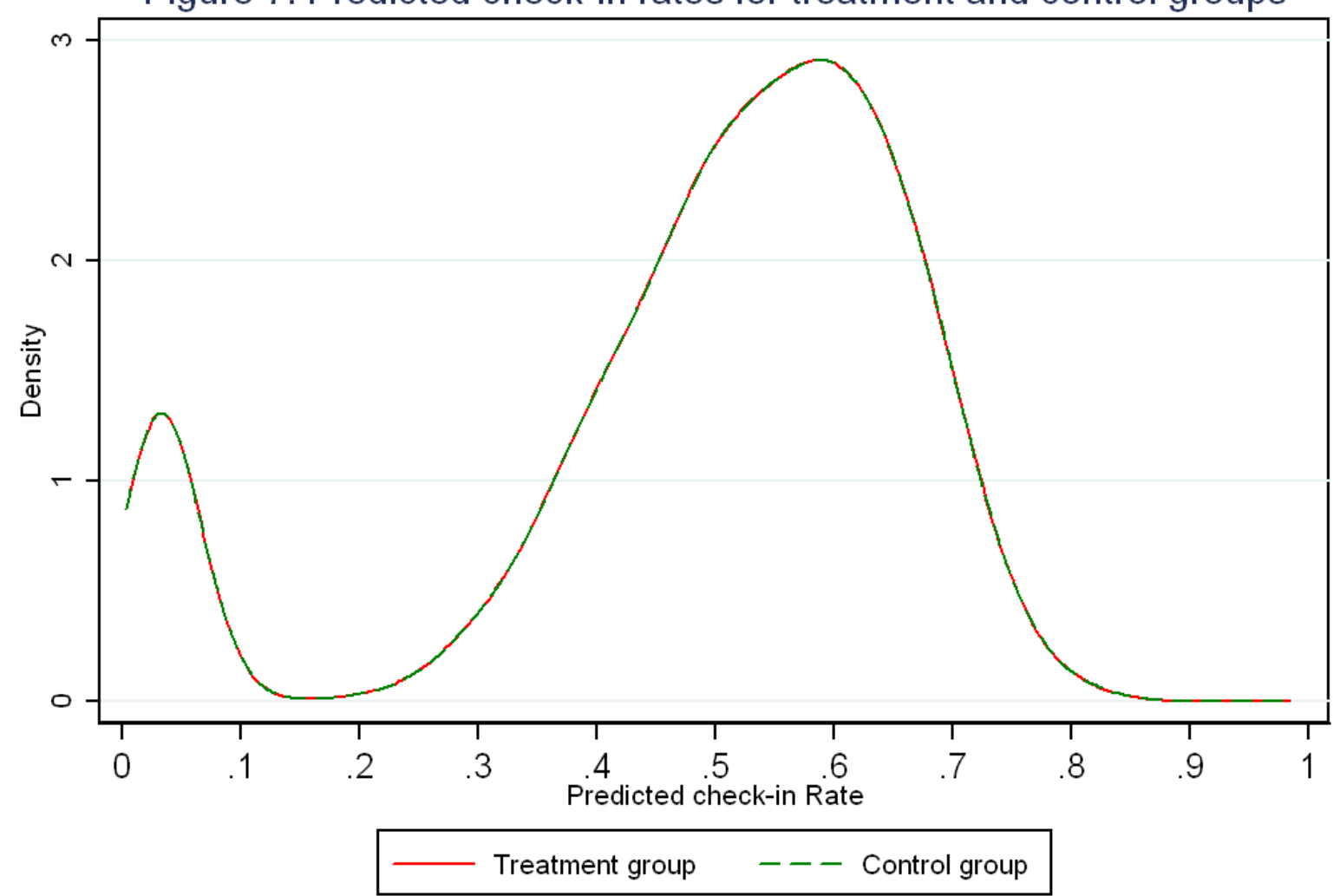

Figure 7 demonstrates we match the treatment distribution very closely with our control group from the comparison set. Second, it also shows a bimodal distribution of predicted probabilities - there are a mass of firms relatively unlikely to respond (maximum around .05) and another more substantial part of the distribution much more likely to respond (maximum around .6). Since we select control firms with replacement, we check how often we selected the same control for different treatment cases and we find we selected a firm at most 24 times. Table 4 shows regression results, where we include all control cases and another specification where we only include each control once ${ }^{14}$. This is equivalent to a weighted versus non-weighted approach in handling the controls. The results show the treatment effect makes firms significantly more

\footnotetext{
${ }^{14}$ For the models in Table 4, in the event of ties in matching a treated firm to controls, we pick a single nearest neighbor. We also ran models that picked the entire set of nearest neighbors when that neighbor wasn't unique, and then we weighted each neighbor equally, with the total weight summing to one for each treatment case.
} 
likely to respond in the Economic Census, and we find that the other variables are for the most part consistent with the results from table 3 that are estimated on the entire population of singleestablishment firms in the Economic Census. Table 5 shows the average effect of the treatment on both the control and treatment groups, based on the estimation results using only the treatment and control firms. The combinations of treatment-treated and control-untreated are observed in the data and match very closely since they were picked that way. They differ slightly since we also include the "treatment" variable to estimate the effect of the treatment, in addition to the original explanatory variables used in table 3 . We estimate roughly a 5 percentage point increase in return rates from the certified mail treatment. Using the predictions from the model which uses each control only once, the effect is closer to a 10 percentage point increase. These two estimates together with the costs provided from the program areas works out to a cost of $\$ 21-\$ 47$ per additional return using certified mail.

\section{Conclusions}

The Census Bureau is working in an environment where it is growing ever more expensive to maintain return rates. It is likely that even with additional resources we could see a decline in return rates. As budget constraints on programs become tighter, program managers will need model-based tools to evaluate which strategies are cost effective at encouraging returns controlling for other factors. Our goal in this paper is to model the check-in status of singleestablishment firms in the 2007 Economic Census. The model allows us to identify a number of characteristics correlated with lower return rates, while controlling for the factors included in the model. We then use the model to evaluate the efficacy of a treatment (certified mailing) 
intended to raise check-in rates. Using propensity score matching to identify a control group, we find that the certified mailing resulted in a 5-10 percentage point higher check-in rate. This implies a cost per additional return of approximately $\$ 21$ to $\$ 47$. Given the lack of sufficiently detailed 2007 paradata about other treatments, such as phone calls to companies, we aren't able to compare the cost effectiveness of other treatments with the certified mailing.

This paper also provides the foundation for a more detailed analysis of the 2012 Economic Census mailout/mailback campaign beginning in the December 2012. For the population under study in this paper, that campaign is described in detail in Appendix B. A new management information system will provide a daily feed of updates on the status of firms, as well as more detailed information about when and how Census contacts firms and vice versa. Building on the static return rate model for 2007, we will combine time series information on the patterns of contact to estimate a hazard model that can be used to predict when firms will respond to the Economic Census. We also plan to use the model to evaluate any treatments planned or unplanned in 2012. For example, given our finding that large single-establishment firms seem to report at lower rates we plan to mail a random sample of the single-establishment firms with over 250 employees a Contact Exchange Card (CEX). The CEX is a program geared towards for large- and medium-sized multi-establishment firms. We mail them during the summer prior to the census mailing in an effort to alert them to the upcoming census and learn who at the company will be responsible for reporting. 


\section{References}

Biffignandi, S. and Pratesi, M., (2002) "Modeling the Respondents' Profile in a Web Survey on Firms in Italy" in Developments in Social Science Methodology, A. Ferligoj and A. Mrvar, ed., Ljubljana: FDV.

Heckman, J., Ichimura, H., Todd, P., (1997). "Matching as an econometric evaluation estimator: evidence from evaluating a job training programme". Review of Economic Studies 64 (4), 605654.

Heckman, J., Ichimura, H., Smith, J., Todd, P., (1998). "Characterizing selection bias using experimental data". Econometrica 66 (5), 1017-1098.

Greene, W. H., (2008), Econometric Analysis, 6th ed. Upper Saddle River, NJ: Prentice-Hall.

Petroni, R., Sigman, R., Willimack, D., Cohen, S.,and Tucker, C., (2004), "Response Rates and Nonresponse in Establishment Surveys - BLS and Census Bureau," Proceedings of the Section on Survey Methods Research, American Statistical Association.

Smith, J. and Todd P. (2005) “Does matching overcome LaLonde's critique of nonexperimental estimators?" Journal of Econometrics 125, 305-353.

Willimack, D.K., Nichols, E., and Sudman, S., (2002) "Understanding Unit and Item Nonresponse in Business Surveys," ch. 14 in Survey Nonresponse, R.M. Groves et al., ed., New York: Wiley.

Willimack, D.K., (2006) "Factors Affecting Early Return Rates on the 2002 Economic Census: Assessing The Impact of the Number of Questionnaire Pages" Proceedings of the Section on Survey Methods Research, American Statistical Association. 
Table 1. 2007 Economic Census Mail-out Schedule

\begin{tabular}{|c|c|c|c|}
\hline Mailing/Follow-up & Number of Firms & Type & Date Range \\
\hline Initial & $1,891,323$ & FORM & $12 / 17 / 07-12 / 21 / 07$ \\
\hline First & 953,011 & FORM & $3 / 4 / 08-3 / 19 / 08$ \\
\hline Second & 687,766 & FORM & $4 / 16 / 08-5 / 1 / 08$ \\
\hline Third & $\begin{array}{c}517,713^{*} \\
(134,047)\end{array}$ & $\begin{array}{c}\text { FORM } \\
\text { (Certified) }\end{array}$ & $6 / 3 / 08-6 / 23 / 08$ \\
\hline Fourth & 356,857 & LETTER & $7 / 18 / 08-8 / 15 / 08$ \\
\hline
\end{tabular}

Source: 2007 paradata from the Mailout and Data Capture Branch, Economic Planning and Coordination Division, U.S. Census Bureau. These numbers exclude the third quarter births in the administrative data from the IRS that is used to update the Business Register during collection and excludes classification forms.

*In addition to mailing a form, the Census Bureau attempted to call 116,925 firms. We do not have paradata on which firms were called. 
Table 2. Model Variables - Description and Source

\begin{tabular}{|c|c|c|}
\hline Variables & Description & Data Source \\
\hline Check-in Status (CI) & $\begin{array}{l}=1 \text { if a form was returned, } \\
=0 \text { otherwise }\end{array}$ & 2007 EC paradata \\
\hline \multicolumn{3}{|l|}{ Business Characteristics } \\
\hline 2002 Reporting Status & $\begin{array}{l}\text { Nonmail, mailed-returned form, } \\
\text { mailed-no form returned }\end{array}$ & 2002 EC microdata \\
\hline Size & $\begin{array}{l}\text { Employment size class dummies: 1-4 } \\
\text { (omitted category), 5-9, 10-19, 20-49, } \\
50-99,100-249,250-499,500+\end{array}$ & $2007 \mathrm{BR}$ \\
\hline Age & $\begin{array}{l}\text { Age class dummies: } 0-1 \text { year (omitted } \\
\text { category), } 2-5,6-10,11-15,16-20,>20\end{array}$ & $\begin{array}{c}\text { Longitudinal Business } \\
\text { Database (LBD) }\end{array}$ \\
\hline Industry & $\begin{array}{l}\text { Six-digit NAICS Industry Indicators, } \\
\text { Franchising }\end{array}$ & $2007 \mathrm{BR}$ \\
\hline Geography & $\begin{array}{l}293 \text { MSA indicators, Micropolitan } \\
\text { dummy, non-metro (omitted category) }\end{array}$ & 2007 EC microdata \\
\hline Owner Characteristics & $\begin{array}{l}\text { Frame Indicators for Black, Asian and } \\
\text { Public ownership (omitted groups are } \\
\text { Female, Hispanic, American Indian, } \\
\text { Hawaiian, National (e.g. white males), } \\
\text { and Other). Frame probabilities of } \\
\text { Hispanic, Black, Asian, and Female. }\end{array}$ & 2007 SBO Frame \\
\hline \multicolumn{3}{|l|}{ External Factors } \\
\hline $\begin{array}{l}\text { County Economic } \\
\text { Conditions }\end{array}$ & $\begin{array}{l}\text { Unemployment rate level and growth, } \\
\text { population, labor force }\end{array}$ & BLS, Census \\
\hline Attitudes toward Census & $\begin{array}{l}2010 \text { Mail-out/Mail-back tract-level } \\
\text { return rates }\end{array}$ & 2010 Decennial \\
\hline $\begin{array}{l}\text { Tract Demographic } \\
\text { Characteristics }\end{array}$ & $\begin{array}{l}\text { Median income, percent Hispanic, } \\
\text { percent Black, percent Asian, percent } \\
\text { linguistically isolated }\end{array}$ & $2008 \mathrm{ACS}$ \\
\hline \multicolumn{3}{|l|}{ Survey Design } \\
\hline $\begin{array}{l}\text { Quality of the Business } \\
\text { Register }\end{array}$ & $\begin{array}{l}\text { Source of the Mail-out NAICS: Bureau } \\
\text { of Labor Statistics (BLS), Migrated } \\
\text { from previous BR (SSEL) in 2001, } \\
\text { Other administrative source (e.g. IRS, } \\
\text { SSA), Census Bureau (omitted } \\
\text { category); tract level geography, } \\
\text { Undeliverable As Addressed status, } \\
\text { third-quarter births }\end{array}$ & $2007 \mathrm{BR}$ and paradata \\
\hline $\begin{array}{l}\text { Characteristics of the } \\
\text { Economic Census } \\
\text { Instruments }\end{array}$ & $\begin{array}{l}\text { Number of pages, number of items, } \\
\text { number/concentration of industries that } \\
\text { reported on the form, share of items by } \\
\text { type (e.g. check-box inquiry) }\end{array}$ & $\begin{array}{c}2007 \text { EC metadata and } \\
\text { paradata }\end{array}$ \\
\hline Treatments & Certified mailing, extensions & 2007 EC paradata \\
\hline
\end{tabular}


Table 3. Logistic Model of 2007 Returns

\begin{tabular}{|c|c|c|c|}
\hline Variables & $\frac{\text { Odds }}{\text { Ratio }}$ & $\frac{\text { Std. }}{\text { Err. }}$ & $\mathbf{t}$ \\
\hline Employment: 5-9 & 1.050 & 0.001 & 47.82 \\
\hline Employment: 10-19 & 1.089 & 0.001 & 67.57 \\
\hline Employment: 20-49 & 1.085 & 0.002 & 52.61 \\
\hline Employment: 50-99 & 1.021 & 0.003 & 8.21 \\
\hline Employment: 100-249 & 0.861 & 0.003 & -42.52 \\
\hline Employment: 250-499 & 0.706 & 0.005 & -51.27 \\
\hline Employment: $>500$ & 0.553 & 0.006 & -58.24 \\
\hline Age: $2-5$ yrs & 1.410 & 0.002 & 214.29 \\
\hline Age: $6-10$ yrs & 1.584 & 0.003 & 253.85 \\
\hline Age: $11-15$ yrs & 1.830 & 0.004 & 291.98 \\
\hline Age: $16-20$ yrs & 2.073 & 0.005 & 315.66 \\
\hline Age: $>20$ yrs & 2.437 & 0.005 & 411.15 \\
\hline No 2002 return x BLS & 0.210 & 0.000 & -896.73 \\
\hline No 2002 return x Non-BLS & 0.189 & 0.002 & -202.78 \\
\hline No 2002 return $x$ SSL & 0.190 & 0.000 & -751.18 \\
\hline 2002 Return x BLS & 0.936 & 0.008 & -7.63 \\
\hline 2002 Return x NonBLS & 1.067 & 0.027 & 2.55 \\
\hline 2002 Return x SSL & 0.976 & 0.010 & -2.47 \\
\hline 2002 No mail x BLS & 0.675 & 0.001 & -341.12 \\
\hline 2002 No mail x Non-BLS & 0.858 & 0.002 & -82.00 \\
\hline 2002 No mail x SSL & 0.837 & 0.001 & -102.12 \\
\hline Log(unemployment rate) & 0.723 & 0.002 & -124.14 \\
\hline$\Delta \log ($ unemployment rate) & 1.385 & 0.005 & 85.17 \\
\hline$\Delta \log ($ labor force $)$ & 1.476 & 0.011 & 52.23 \\
\hline Asian frame & 0.787 & 0.001 & -222.74 \\
\hline Asian probability & 0.999 & 0.002 & -0.46 \\
\hline Black frame & 0.739 & 0.001 & -191.75 \\
\hline Black probability & 0.502 & 0.002 & -191.95 \\
\hline Hispanic probability & 0.594 & 0.001 & -263.45 \\
\hline Female probability & 1.104 & 0.001 & 76.93 \\
\hline \# Pages & 0.912 & 0.001 & -103.64 \\
\hline \# Items & 0.999 & 0.000 & -28.03 \\
\hline$\%$ Write-in items & 0.150 & 0.004 & -63.45 \\
\hline$\%$ Dollar items & 1.833 & 0.040 & 27.86 \\
\hline \% Checkbox items & 0.376 & 0.007 & -52.05 \\
\hline \# Write-in characters & 1.000 & 0.000 & 50.94 \\
\hline Industry form count & 1.031 & 0.000 & 70.03 \\
\hline Industry form HHI & 1.000 & 0.000 & 9.78 \\
\hline
\end{tabular}




\begin{tabular}{|l|c|c|c|}
\hline No tract x UAA & 0.026 & 0.000 & -1463.66 \\
\hline Tract x No UAA & 0.992 & 0.001 & -7.29 \\
\hline Tract x UAA & 0.032 & 0.000 & -847.98 \\
\hline Third Quarter Birth & 0.451 & 0.001 & -502.03 \\
\hline Extension of Reporting Deadline & 1.322 & 0.002 & 165.90 \\
\hline Public Company frame & 0.955 & 0.004 & -9.88 \\
\hline Industry controls & \multicolumn{3}{|c|}{ yes - six-digit NAICS } \\
\hline Geography controls & \multicolumn{3}{|c}{ yes - 293 Metro, 1 Micro } \\
\hline Number of observations & \multicolumn{3}{|c}{} \\
\hline
\end{tabular}


Table 4. Return Model on Certified Mail Treatment and Control

\begin{tabular}{|c|c|c|c|c|}
\hline \multirow[b]{2}{*}{ Variables } & \multicolumn{2}{|c|}{$\begin{array}{l}\text { Nearest Neighbor } \\
\text { - ALL }\end{array}$} & \multicolumn{2}{|c|}{$\begin{array}{l}\text { Nearest Neighbor } \\
\text { - Duplicates } \\
\text { Dropped }\end{array}$} \\
\hline & 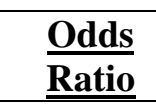 & $\frac{\text { Std. }}{\text { Err. }}$ & $\underline{\text { Odds }}$ & $\underline{\text { Std. }}$ \\
\hline Employment: 5-9 & 1.054 & 0.023 & 1.055 & 0.023 \\
\hline Employment: 10-19 & 1.040 & 0.028 & 1.019 & 0.026 \\
\hline Employment: $20-49$ & 0.935 & 0.029 & 0.928 & 0.029 \\
\hline Employment: 50-99 & 0.813 & 0.035 & 0.814 & 0.035 \\
\hline Employment: 100-249 & 0.705 & 0.036 & 0.686 & 0.032 \\
\hline Employment: 250-499 & 0.559 & 0.065 & 0.511 & 0.050 \\
\hline Employment: > 500 & 0.500 & 0.078 & 0.531 & 0.091 \\
\hline Age: $2-5 \mathrm{yrs}$ & 1.779 & 0.059 & 1.793 & 0.057 \\
\hline Age: $6-10 \mathrm{yrs}$ & 1.980 & 0.073 & 2.023 & 0.074 \\
\hline Age: $11-15$ yrs & 2.178 & 0.082 & 2.227 & 0.083 \\
\hline Age: $16-20$ yrs & 2.283 & 0.083 & 2.332 & 0.084 \\
\hline Age: $>20$ yrs & 2.414 & 0.093 & 2.472 & 0.093 \\
\hline No 2002 return x BLS & 0.514 & 0.019 & 0.532 & 0.019 \\
\hline No 2002 return $x$ Non-BLS & 0.519 & 0.039 & 0.528 & 0.040 \\
\hline No 2002 return $x$ SSL & 0.531 & 0.018 & 0.537 & 0.016 \\
\hline 2002 Return x BLS & 0.828 & 0.094 & 0.949 & 0.082 \\
\hline 2002 Return $\mathrm{x}$ NonBLS & 1.132 & 0.361 & 0.835 & 0.253 \\
\hline 2002 Return x SSL & 1.056 & 0.087 & 1.070 & 0.078 \\
\hline 2002 No mail x BLS & 0.796 & 0.019 & 0.818 & 0.019 \\
\hline 2002 No mail x Non-BLS & 0.748 & 0.036 & 0.757 & 0.036 \\
\hline 2002 No mail x SSL & 0.823 & 0.032 & 0.831 & 0.034 \\
\hline Log(unemployment rate) & 0.844 & 0.033 & 0.840 & 0.031 \\
\hline$\Delta \log ($ unemployment rate) & 1.306 & 0.072 & 1.346 & 0.070 \\
\hline$\Delta \log ($ labor force $)$ & 1.386 & 0.161 & 1.429 & 0.149 \\
\hline Asian frame & 0.838 & 0.014 & 0.839 & 0.013 \\
\hline Asian probability & 1.266 & 0.045 & 1.267 & 0.042 \\
\hline Black frame & 0.829 & 0.020 & 0.829 & 0.018 \\
\hline Black probability & 0.778 & 0.043 & 0.784 & 0.042 \\
\hline Hispanic probability & 0.838 & 0.030 & 0.826 & 0.027 \\
\hline Female probability & 1.025 & 0.023 & 1.034 & 0.020 \\
\hline \# Pages & 0.915 & 0.016 & 0.925 & 0.015 \\
\hline \# Items & 1.000 & 0.001 & 0.999 & 0.001 \\
\hline$\%$ Write-in items & 0.378 & 0.345 & 0.313 & 0.266 \\
\hline$\%$ Dollar items & 1.881 & 1.802 & 2.881 & 2.694 \\
\hline
\end{tabular}




\begin{tabular}{|c|c|c|c|c|}
\hline$\%$ Checkbox items & 0.874 & 0.756 & 1.098 & 0.905 \\
\hline \# Write-in characters & 1.001 & 0.000 & 1.000 & 0.000 \\
\hline Industry form count & 1.091 & 0.027 & 1.075 & 0.027 \\
\hline Industry form HHI & 1.000 & 0.000 & 1.000 & 0.000 \\
\hline No tract $x$ UAA & 0.023 & 0.002 & 0.023 & 0.001 \\
\hline Tract $x$ No UAA & 1.023 & 0.020 & 1.029 & 0.018 \\
\hline Tract $\mathrm{x}$ UAA & 0.032 & 0.004 & 0.031 & 0.003 \\
\hline Public Company frame & 0.898 & 0.047 & 0.913 & 0.043 \\
\hline Certified Mailing Treatment & 1.315 & 0.153 & 1.788 & 0.190 \\
\hline Industry controls & \multicolumn{2}{|c|}{ yes } & \multicolumn{2}{|c|}{ yes } \\
\hline Geography controls & \multicolumn{2}{|c|}{ yes } & \multicolumn{2}{|c|}{ yes } \\
\hline Number of observations & \multicolumn{2}{|c|}{258,422} & \multicolumn{2}{|c|}{215,051} \\
\hline Pseudo $\mathrm{R}^{2}$ & \multicolumn{2}{|c|}{0.1375} & \multicolumn{2}{|c|}{0.1306} \\
\hline
\end{tabular}


Table 5. Predictive Margins: Treated vs. Control; Treated vs. Not Treated

\begin{tabular}{|l|c|c|}
\hline & Treated & Not Treated \\
\hline \multicolumn{3}{|c|}{ Nearest Neighbor - ALL } \\
\hline Treated Firms & $\begin{array}{c}.499 \\
(.004)\end{array}$ & $\begin{array}{c}.441 \\
.021)\end{array}$ \\
\hline Control Firms & $\begin{array}{c}.551 \\
(.020)\end{array}$ & $\begin{array}{c}.494 \\
(.004)\end{array}$ \\
\hline Nearest Neighbor - Duplicates Dropped \\
\hline Treated Firms & $\begin{array}{c}.499 \\
(.002)\end{array}$ & $\begin{array}{c}.376 \\
(.020)\end{array}$ \\
\hline Control Firms & $\begin{array}{c}.582 \\
(.018)\end{array}$ & $\begin{array}{c}.461 \\
(.004)\end{array}$ \\
\hline
\end{tabular}


Appendix A. Counts of Certified Third Follow-up by Form Number

\begin{tabular}{|c|c|c|c|}
\hline$\underset{\text { Form }}{\text { Number }}$ & $\frac{\text { Processing }}{\text { Division }}$ & $\frac{\text { Date Files }}{\text { Created }}$ & $\frac{\text { Approximate }}{\text { Count }}$ \\
\hline 23601 & $\overline{M C D}$ & $6 / 13 / 2008$ & 9486 \\
\hline 23701 & MCD & $6 / 13 / 2008$ & 2629 \\
\hline 23801 & MCD & $6 / 9 / 2008$ & 6402 \\
\hline 23802 & MCD & $6 / 9 / 2008$ & 6497 \\
\hline 23803 & MCD & 6/9/2008 & 5614 \\
\hline 23804 & MCD & 6/9/2008 & 3237 \\
\hline 31120 & MCD & $6 / 10 / 2008$ & 1363 \\
\hline 31505 & MCD & $6 / 9 / 2008$ & 1728 \\
\hline 32301 & MCD & $6 / 13 / 2008$ & 1466 \\
\hline 32371 & MCD & $6 / 9 / 2008$ & 2432 \\
\hline 42403 & SSSD & $6 / 6 / 2008$ & 1631 \\
\hline 44201 & SSSD & $6 / 9 / 2008$ & 2609 \\
\hline 44501 & SSSD & 6/9/2008 & 11791 \\
\hline 44601 & SSSD & $6 / 9 / 2008$ & 3818 \\
\hline 44801 & SSSD & $6 / 9 / 2008$ & 3603 \\
\hline 44803 & SSSD & $6 / 10 / 2008$ & 783 \\
\hline 45101 & SSSD & $6 / 10 / 2008$ & 2418 \\
\hline 45201 & SSSD & $6 / 10 / 2008$ & 1999 \\
\hline 45401 & SSSD & $6 / 10 / 2008$ & 3362 \\
\hline 48460 & SSSD & $6 / 6 / 2008$ & 10812 \\
\hline 51106 & SSSD & $6 / 12 / 2008$ & 972 \\
\hline 51702 & SSSD & $6 / 12 / 2008$ & 2949 \\
\hline 52206 & SSSD & $6 / 11 / 2008$ & 6466 \\
\hline 52360 & SSSD & $6 / 11 / 2008$ & 8503 \\
\hline 53101 & SSSD & $6 / 5 / 2008$ & 8301 \\
\hline 54107 & SSSD & $6 / 4 / 2008$ & 4697 \\
\hline 54116 & SSSD & $6 / 4 / 2008$ & 3594 \\
\hline 54119 & SSSD & $6 / 4 / 2008$ & 2152 \\
\hline 56101 & SSSD & $6 / 13 / 2008$ & 2649 \\
\hline 56106 & SSSD & $6 / 9 / 2008$ & 1348 \\
\hline 62106 & SSSD & $6 / 13 / 2008$ & 985 \\
\hline 71103 & SSSD & $6 / 11 / 2008$ & 1566 \\
\hline 71304 & SSSD & $6 / 11 / 2008$ & 333 \\
\hline 72202 & SSSD & $6 / 12 / 2008$ & 1263 \\
\hline Total & & & 129458 \\
\hline
\end{tabular}

